\title{
Analysis of the Effects of Frequent Increases of the Reserve Requirement Ratio by the People's Bank of China*
}

\author{
Haiying Pan, Huan Song, Yu Wang, Yangyang Hu \\ School of Business, Hohai Universisy, Nanjing, China \\ Email: hypan@hhu.edu.cn, songhuan280@163.com, \{877863891,443159680\}@qq.com
}

Received January 4, 2012; revised February 15, 2012; accepted February 24, 2012

\begin{abstract}
The legal required reserves system is a monetary policy that is used by central banks to perform macroeconomic adjustments. In China, the required reserves system is one of the most important policies of the People's Bank of China. In this study, using information from the Vector Auto-Regression Model and utilizing monthly data of the reserve requirement ratio (RRR), money supply, Consumer Price Index (CPI), and loan scale from January 2006 to March 2011, we quantitatively studied the effects of frequent increases in the RRR in China. We found that China's monetary policy regarding required reserves has not had a significant effect on dealing with excess liquidity, preventing inflation or controlling increases in the loan scale. We briefly analyzed the reasons for the limited actual effects of China's required reserves policy regarding the required reserves system, monetary transmission mechanism, system of forced RMB sale, and purchase of foreign exchange.
\end{abstract}

Keywords: Reserve Requirement Ratio; Excess Liquidity; Vector Auto-Regression Model

\section{Introduction}

The legal required reserves system, which has historically been used to achieve macroeconomic adjustments and control, has been one of the major monetary policies of central banks in many countries. Through many years of development, the function of the current required reserves system has evolved from liquidity guarantees to loan scale control, from loan scale control to money supply control, from money supply control to financial environment stabilization, and from financial environment stabilization to indirect regulation and control of interest rates [1]. According to the practices of developed countries, the system's effects on the operation of monetary policy have tended to decrease. For instance, the United States, some European countries, and Japan still use the required reserves system; however, these countries' central banks have not adopted this system as a monetary policy tool, and legal required reserve levels have dropped substantially. Some countries, such as the United Kingdom, Canada, and Australia, have implemented a zero reserve fund system; that is, their central banks do not have authority over the reserve funds of commercial banks.

China is a developing country, and its required reserves system is one of the most important monetary

"Fund Project: Supported by "the Fundamental Research Funds for the Central Universities” (2009B22414). policies of its central bank. Since 2006, to curb excess liquidity, increasing inflation pressure, a soaring bank loan scale, and other problems, the People's Bank of China (PBOC) has implemented macroeconomic regulation and control by frequently increasing the reserve requirement ratio (RRR). Figure 1 illustrates the introduction of RRR adjustment from January 2006 to March 2011.

As indicated in Figure 1, the RRR was increased 27 times from January 2006 to March 2011 (it only decreased twice during the 2008 financial crisis) and reached a historical peak of $20.0 \%$. During this period, China's money supply, Consumer Price Index (CPI), and loan scale maintained a tendency toward constant growth. The data indicate that the average annual growth rates of the money supply and loan scale from 2006 to 2010 were $24.4 \%$ and $24.5 \%$, respectively, while the CPI increased by $16.6 \%{ }^{1}$.

These findings indicate that the effects of China's monetary policy on required reserves must be questioned. It is necessary to conduct an intensive study on the effectiveness of China's required reserves policy. This paper is structured in the following manner: Part 2 introduces the literature related to the adjustment of China's required reserves. Part 3 introduces data and research methods. Part 4 contains a specific analysis of the empirical results and an explanation of why China's required re-

\footnotetext{
${ }^{1}$ We took January 2006 as the base period in analysis.
} 


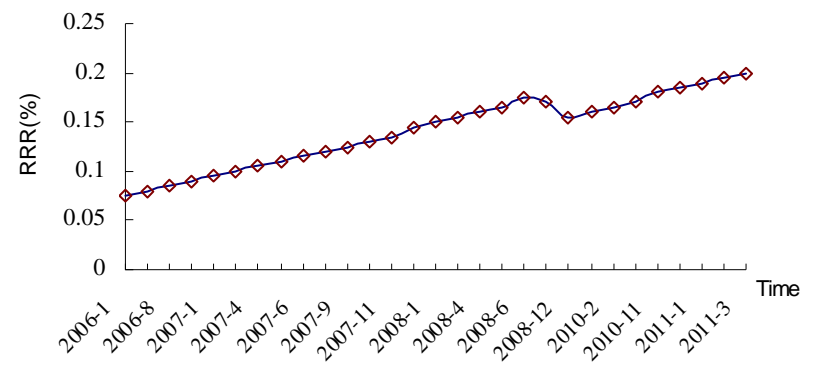

Figure 1. RRR from January 2006 to March 2011.

serves policy has failed to realize its desired effects on the central bank. Part 5 presents conclusions and future research directions.

\section{Literature Review}

In recent decades, few developed countries have used directly required reserves systems as monetary policy tools. However, in recent years, some meaningful international studies have been conducted about the relationships among required reserves systems, monetary policy, interest rate control, and the ability of commercial banks to create credit.

Richard and Kenneth (1983) studied RRR changes on the money supply in the short term and concluded that the adjustment of the RRR affects the expected value and supply of money [2]. Weiner (1992) suggested that countries should focus their monetary policy on interest rate control. Central banks should make controlling market interest rates the main short-term goal of monetary policy, but their long-term target should be money supply control. Therefore, the required reserves policy is not only a direct tool for money supply control, but it is also a convenient tool for short-term market interest rate control [3]. Starting from the response of the required reserves and funds rate to an adjustment under different monetary policy objectives, Leeper et al. (1996) and Bernanke and Mihov (1998) empirically identified monetary policy targets in the United States. They studied the shock of monetary policy on the economy and the shock of the economy on monetary policy. They also analyzed whether monetary policy targets fully impacted the innovation of the economic system and monetary policy changes [4,5].

By studying the short-term volatility of market interest rates in countries that cancelled their required reserves systems, (Canada, the United Kingdom, and New Zealand) Gordon and Stuart (1997) concluded that the observed volatility of interest rates in these countries largely came from institutional adjustments. However, the volatility of interest rates was not associated with zero required reserves, according to this research [6]. Analyzing the influencing factors of the RRR and the effects of required reserve adjustment, James (1998) concluded that raising the RRR would raise interest rates, which would further affect financial markets [7]. Goodfriend (2002) pioneered the concept of the "required reserve payments system". He suggested that the required reserve payments system could be transformed into a monetary policy tool as important as an open-market operation and could be used to control short-term interest rates more broadly and efficiently than the current Federal Funds Rate [8].

Tobin et al. (1963) analyzed the relationship between the required reserves system and the ability of commercial banks to create money, but they did not directly emphasize the importance of the required reserves system during the act of money creation by commercial banks. They concluded that money creation by commercial banks was restricted by the principle of the margin benefit equal to the margin cost. Commercial banks only acted as risk-neutral portfolio managers in the process of creating money, and the required reserves system only worked indirectly through use of the cost-benefit principle [9].

We found that few international studies have been conducted on the actual effects of the frequent increases in the RRR by the PBOC; therefore, little relevant literature exists on the subject. In recent years, some studies have been conducted in China on the adjustment of the central bank's required reserves from different perspectives.

Most current studies are concerned with the macroeconomic effects of China's RRR adjustments. Based on the Constitution of the Reserve Fund of the Commercial Bank and the basic model of the modern money supply theory, Shi (2008) analyzed the impact of China's required reserves policy on the money supply and concluded that the impact of the required reserves policy on the money supply was limited [10]. Luo (2010) analyzed the effects of China's required reserves policy during the period of 2006-2008 and concluded that the increase in the required reserves has had a direct impact on the excess reserve fund and monetary base. However, the money supply, monetary multipliers, and interest rates are strongly influenced by financial institutions and other economic entities; thus, the impact of an increase in the required reserves is not in complete agreement with the theoretical model. Under conditions of a market economy, it is not suitable for China to depend excessively on its required reserves policy for economic adjustment [11]. $\mathrm{Wu}$ (2010) made a comparative analysis of the causes of all previous RRR adjustments by the PBOC and the macroeconomic effects since the second half of 2006. The study concluded that because depending on required reserves would make it difficult to completely recover surplus liquidity, excess liquidity must be dealt with through the combined application of many monetary 
policy tools and the implementation of macroscopic readjustment and control policies [12]. Zhao et al. (2008) analyzed the macroeconomic background of the increase in the required reserves by the PBOC in November 2007 and discussed the macro effect of this increase on the banking industry, stock market, and real estate market. They concluded that this monetary policy would not generate an obvious impact on the operation of the entire macro economy and that its actual effect on inflation restraint would be limited [13]. Li (2008) analyzed the main causes of increases in the RRR since 2004 and the problems that exist in using the required reserves policy. He concluded that simply increasing required reserves is not sufficient to solve the structural problems of China's economic development [14].

Some studies have focused on how to improve the effectiveness of RRR adjustment by the PBOC. Yang (2008) suggested that defects in the financial system were constraints on the effectiveness of China's required reserves and indicated that the realization of the Ren Min $\mathrm{Bi}$ (RMB) exchange rate flotation, marketization of interest rates, and improvement of the required reserves system were important for enhancing the effectiveness of required reserves adjustment [15]. Cui and Liu (2009) researched the mechanism of action of the required reserves system on the basis of the endogenous money supply theory and analyzed the gap between the actual effect of 19 increases of the legal required reserves made by the PBOC from 2006 to June 2008 and the expected goal of regulation and control. He concluded that there is no causal relationship among China's required reserves, loan scale, and money supply [16].

Most studies related to required reserves have been primarily based on qualitative analyses, so quantitative studies related to the actual effects of increases in China's RRR in recent years are lacking. From the perspective of quantification, this study aims to investigate the impact of increases in RRR on China's macroeconomy, which will be beneficial for selecting and formulating an optimum monetary policy and aiding in the long-term and stable development of China's economy.

\section{Data and Research Method}

\subsection{Variables}

This study analyzed the effects of increases in the RRR in China from three aspects: the impact of RRR increases on the money supply, the impact of RRR increases on the inflation level, and the relationship between RRR increases and the loan scale. Therefore, the primary variables employed in this study were the RRR, money supply, inflation level, and loan scale.

To estimate and understand the money supply in circulation and more effectively regulate and control it ac- cording to the scope of currency coverage and differences in liquidity, the International Monetary Fund (IMF) provides the following categories of money supply: M0 (cash), M1 (narrow money) and M2 (broad money). By referring to general international principles and China's actual situation, the People's Bank of China also divides China's money supply indicators into the three categories of M0, M1 and M2. In detail, M0 refers to cash in circulation, M1 includes M0 and current deposits of enterprises and public institutions, and M2 includes M1, savings deposits of citizens, fixed deposits of enterprises and public institutions, and foreign currency deposits. M2 is of great significance for researching the overall situation of currency circulation. In recent years, many countries have begun to focus on M2 for the regulation and control of the money supply. Therefore, in this study, we use M2 to represent the money supply.

Common indicators for measuring the inflation level include the CPI, Cost of Living Index (CLI), Producer Price Indexes (PPI), GDP Deflator, and Personal Consumption Expenditures Price Index (PCEPI). Among these indicators, the CPI is an index that integrates consumer goods variations (reflecting fluctuations in basic commodity price levels), which generally represents an important index for judging the inflation level. However, the CPI is only similar to the inflation rate in terms of one spatial dimension. To measure the entire inflation level comprehensively and authentically, it is more suitable to adopt the GDP deflator. However, because of the lag in statistical data when economic situations are analyzed, scholars frequently measure the inflation level using the CPI. Thus, in this study, we measured the inflation level using the CPI.

In this study, we used monthly statistical data from January 2006 to March 2011. Information on the RRR, money supply (M2), loan scale (LS), and other data came from the People's Bank of China [17]. The basic data for the CPI were taken from the National Bureau of Statistics [18]. The monthly CPI is currently formulated in China on a year-to-year index; to meet the demands of this study, we transformed it into a fixed base index (January $2006=100$ ). To stabilize the time series, we used a logarithm, the sequence of which is LRRR, LM2, LCPI and LLS.

\subsection{Research Method and Framework}

This study primarily used Vector Auto-Regression (VAR), the Johansen cointegration test, the Granger causality test, and an analysis of the actual effect of an RRR increase with the Impulse Response Function. VAR is an effective prediction model for an interrelated time series variable system. When each variable plays a role in predicting other variables, the group of variables is suitable for rep- 
resentation by the VAR model [19].

$$
Y_{t}=A_{1} Y_{t-1}+A_{2} Y_{t-2}+\cdots+A_{N} Y_{t-N}+B X_{t}+\varepsilon_{t}
$$

In the VAR model, each equation in the system has the same variables on the right of the equation, including the lagged values of all variables. As it is difficult to explain the VAR single-parameter estimated value, we generally made conclusions for the VAR model by observing the Impulse Response Function (IRF) and variance decomposition of the system. This study mainly used IRF to explain the VAR model, which depicts the response of the endogenous variable to the level of error variation; in other words, it depicts the influence of the error term and the one-standard-deviation shock on the current and future values of the endogenous variable.

The empirical research framework of this study is described in the following manner. 1) Establish the preliminary VAR model. The minimum norms of the AIC and SC values determine the optimal lag period of the VAR model; 2) Apply the Johansen cointegration test to judge whether a long-term and stable relationship exists among multiple variables. In addition, determine the causality relationships among variables by means of the Granger causality test; 3) Utilize the AR root diagram to perform a stability test for the models in a selected lag duration. If the VAR model is stable, then utilize the IRF to calculate the responses of LM2, LCPI, and LLS to a one-standard-deviation shock of the LRRR. All empirical analyses in this study were conducted using the Eviews 5.1 software program.

\section{Results and Analysis}

\subsection{Empirical Results and Analysis}

\subsubsection{Johansen Cointegration Test}

The Augmented Dickey-Fuller (ADF) approach was used to conduct a stability test for time series data for LRRR, LM2, LCPI, and LLS; the results indicated that all were unstable at a significance level of 5\%; however, after the first-order difference, each variable was stable. Therefore, LRRR, LM2, LCPI, and LLS belong to a first-order integrated unstable series. This finding implies that they may have a cointegration relationship and a long-term equilibrium relationship. Because four variables were used in this study, the Johansen cointegration test was employed.
Prior to conducting the Johansen cointegration test, the structure of VAR was determined. To establish an unrestricted preliminary VAR model, the VAR(5) model was established for four evaluation statistics among the values of LR, FRP, AIC, SC, and HQ; the optimal lag duration is five phases. Then, an appropriate cointegration test model was determined with a duration of four lag phases and a constant term. The Johansen cointegration test results are presented in Table $\mathbf{1 .}$

Judging from the test significance level of 0.05 , the Trace statistics, and the Max-Eigen statistics test results presented, Table 1 indicates that at least two cointegration equations exist among the LRRR, LM2, LCPI, and LLS series, which implies that a long-term stable relationship exists among the variables.

\subsubsection{Granger Causality Test}

The cointegration test results indicate that a long-term equilibrium relationship exists among all data series; however, the causality relationship could not be evaluated. Therefore, the Granger causality test was implemented for variables on the basis of the cointegration test. The lag order was defined as five according to the AIC norm for the Granger causality test. The test results are presented in Table 2.

Table 2 illustrates our finding (with 95\% confidence) that the occurrence probability of the null hypothesis "LRRR is not a Granger-cause of LM2" is 0.04211; therefore, the null hypothesis is rejected. In other words, LRRR is a Granger-cause of LM2; variation in the RRR will bring about variation in the money supply. We also found that LRRR is the Granger-cause of LLS variation, but LRRR is not a Granger-cause of LCPI variation. However, LCPI variation enables LRRR to change. This finding implies that after the RRR changes, the loan scale will change accordingly, and CPI variation will cause the PBOC to adjust the RRR.

\subsubsection{Impulse Response Function Analysis}

To further analyze the relationship between LRRR and LM2, LCPI, and LLS, this study adopted the IRF based on the VAR model. Analysis of the AR root diagram indicated that all roots in $\operatorname{VAR}(5)$ were less than 1 , and it was a stable system that could be used for impulse analysis and variance decomposition.

Table 1. Results of Johansen cointegration test.

\begin{tabular}{cccccccc}
\hline Hypothesized No. of CE(s) & Eigenvalue & Trace Statistic & 0.05 Critical Value & Prob.** & Max-Eigen Statistic & 0.05 Critical Value & Prob.** \\
\hline None* & 0.445398 & 70.86185 & 47.85613 & 0.0001 & 34.19128 & 27.58434 & 0.0061 \\
At most 1* & 0.368894 & 36.67056 & 29.79707 & 0.0069 & 26.69630 & 21.13162 & 0.0074 \\
At most 2 & 0.115960 & 9.974261 & 15.49471 & 0.2827 & 7.148666 & 14.26460 & 0.4717 \\
At most 3 & 0.047550 & 2.825595 & 3.841466 & 0.0928 & 2.825595 & 3.841466 & 0.0928 \\
\hline
\end{tabular}


Table 2. Results of Granger causality test.

\begin{tabular}{cccc}
\hline Null Hypothesis: & Obs & F-Statistic & Probability \\
\hline LM2 does not Granger Cause LRRR & 58 & 0.95533 & 0.45468 \\
LRRR does not Granger Cause LM2 & & 2.52118 & 0.04211 \\
LCPI does not Granger Cause LRRR & 58 & 3.26914 & 0.01294 \\
LRRR does not Granger Cause LCPI & & 0.62382 & 0.68231 \\
LLS does not Granger Cause LRRR & 58 & 0.79259 & 0.56043 \\
LRRR does not Granger Cause LLS & & 3.03994 & 0.01855 \\
\hline
\end{tabular}

Figure 2 presents the impulse response function diagram of LM2. This figure shows that LM2 has a negative response to one-standard-deviation shock of the LRRR in the current period. RRR variation will immediately lead to a reverse variation in the money supply. Furthermore, such an influence will last for a long period of time. However, we also noticed that this influence is very weak because the maximum value (in the $4^{\text {th }}$ month) of the negative impulse response of LM2 is only 0.005 . Thus, the impulse response value will phase down until the influence disappears in the $19^{\text {th }}$ month and will then become a positive response. This result indicates that in the inflation period, the PBOC achieved some effects on liquidity contraction over a relatively long period by actively increasing the RRR; however, the effects are not obvious. Therefore, the effects of the PBOC's control of the money supply with a required reserves policy are not significant, and China's money supply is not represented as an exogenous feature.

Figure 3 presents the IRF diagram of LCPI. This figure indicates that during the study, LCPI did not show the expected negative response for one-standard-deviation shock of the LRRR; rather, a positive response came

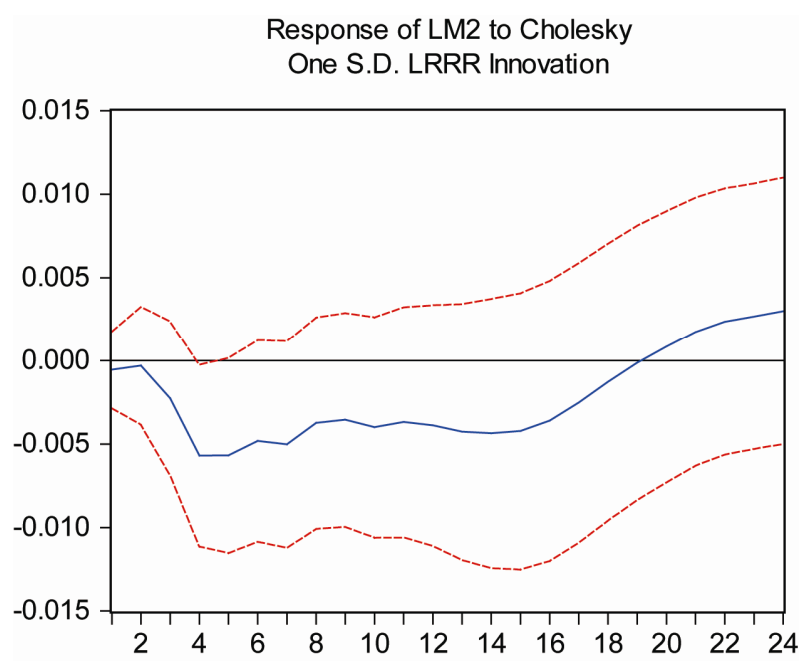

Figure 2. Impulse response of LM2 to one standard deviation shock of LRRR.

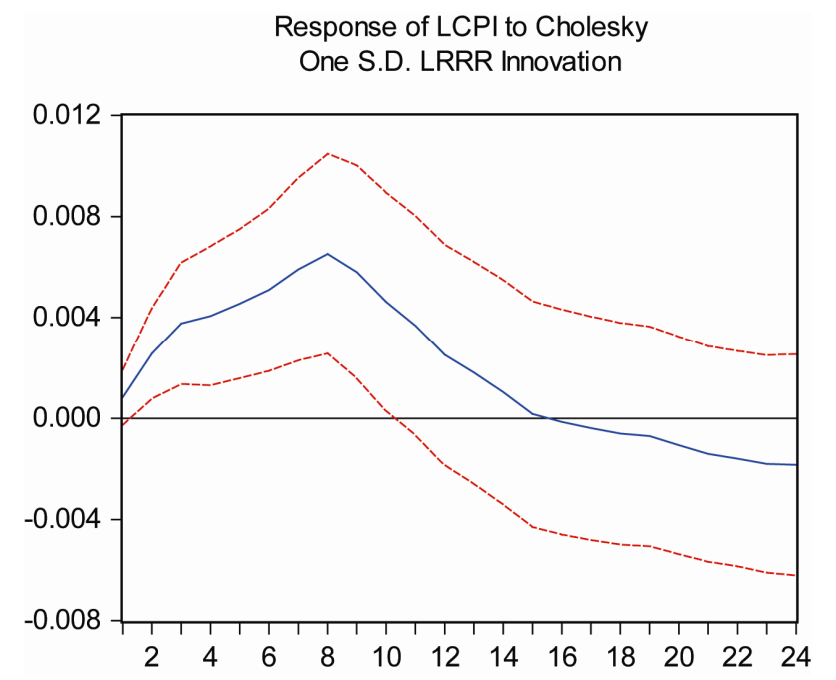

Figure 3. Impulse response of LCPI to one standard deviation shock of LRRR.

first and gradually turned into a negative response after the $15^{\text {th }}$ month. This finding indicates that in the inflation period, the PBOC's control of the exorbitant CPI by increasing the RRR was ineffective over a relatively long period. Even though the impulse response value of LCPI after the $15^{\text {th }}$ month is less than 0 , its impact is very weak. Therefore, the excessively high CPI cannot be corrected simply by adjusting the RRR.

Figure 4 presents the impulse response function diagram of LLS. LLS had a negative response for twenty consecutive months for one-standard-deviation shock of the LRRR; the RRR variation has a relatively long period of impact on variations in the loan scale. We also found that such an impact is weak because the negative impulse response value of LLS reached the maximum value $(0.007)$ in the $7^{\text {th }}$ month. Thereafter, it gradually dropped and the impact decreased to 0 until the $20^{\text {th }}$ month. This result indicates that in the inflation period, RRR increases generate some effects for controlling the loan scale over a relatively long period in China; however, the effects are significant. Furthermore, over time, such an influence gradually loses its effectiveness. 


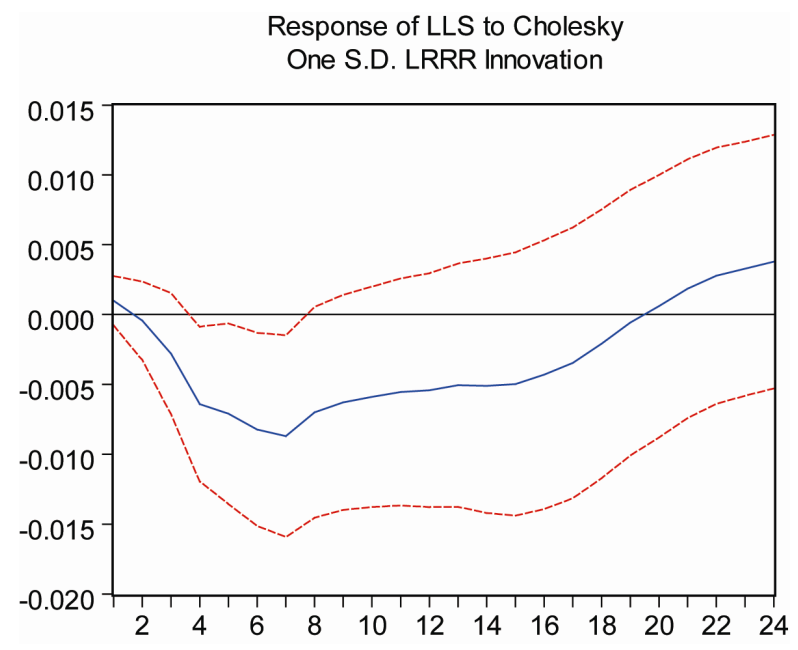

Figure 4. Impulse response of LLS to one standard deviation shock of LRRR.

\subsection{Analysis of the Reasons for the Indistinct Effects of the Required Reserves Policy}

The above empirical results indicate that long-term, stable equilibrium relationships exist among RRR, M2, CPI, and LS. However, increases in the RRR that have been made by the PBOC have little effect on curbing excess liquidity and controlling the loan scale and are almost completely ineffective in restraining inflation. The PBOC has employed the monetary policy of changing required reserves for macroeconomic regulation and control, but it has not achieved the expected results. The reasons for this lack of success are discussed in the following account.

The differential required reserves system is not flexible. After April 2004, China began to implement a differential required reserves system, mainly indicating that the RRR of commercial banks was associated with the capital adequacy ratio and capital quality. However, the current required reserves system does not stipulate different RRRs according to different regions, types of liabilities or liquidity situations of commercial banks. These defects in the system influence the effects of the RRR policy.

Furthermore, the interest payment system has impacted the effects of the required reserves policy. The practice of China adopting interest payments for required reserves is inconsistent with the practices of many other countries. The cost of a commercial bank taking deposits is lower than the profit gained from the deposited capital. Therefore, a commercial bank is motivated to deposit capital in the form of reserve funds in the central bank to gain risk-free profit, which influences the monetary policy efficiency of the PBOC and reduces the effectiveness of the RRR as a monetary policy tool.

The effectiveness of the monetary transmission mecha- nism has not been reflected. The impact of variations in the RRR on the monetary multiplier is not evident. The monetary multiplier model indicates that the RRR has an inverse relationship with the monetary multiplier and money supply. However, quantitative research on the monetary multiplier and its influencing factors has indicated that the influence of a legal variation in the RRR is very weak for monetary multiplier variation. If the monetary base is left unchanged, then an RRR adjustment will not greatly influence the money supply. On the other hand, research has revealed that the contributions of the monetary multiplier to the money supply are small; the increase in the money supply depends mainly on the expansion of the monetary base rather than on variations in the monetary multiplier [20]. The RRR achieves the purpose of money supply regulation mainly by changing the value of the monetary multiplier and combining the existing research results; therefore, as a monetary policy tool, China's required reserves system will have little effect on the regulation of the money supply.

The existence of large excess reserves has a significant influence on the actual effect of the legal RRR adjustment in China. Since 2006, legal required reserves have continuously increased, while excess RRR has gradually fallen. During this time, the large deposit base number of China's commercial banks has caused excess reserves, which have remained adequate: their absolute sum exceeded 1 trillion RMB Yuan in 2010. In fact, increases in the legal RRR have only caused excess reserves to reduce correspondingly, and it is very difficult to generate an obvious, substantial influence on money supply contraction.

Counterpart foreign exchange reserves led by forced sales and purchases of foreign exchange have largely offset the effect of the required reserves policy. In recent years, under the pressure of an enormous trade surplus and large offshore funds, China encountered an immense double surplus situation in its current and capital accounts. However, given the forced sale and purchase of foreign exchange, the PBOC must now constantly buy foreign exchange sold by commercial banks, which results in a constant increase in the foreign exchange reserve. The data indicate that from January 2006 to December 2010, the proportion of foreign exchange held by the monetary authority that accounted for total assets increased from $60.1 \%$ to $79.8 \%$ and amounted to $80.4 \%$ by February 2011. An increase in the counterpart foreign exchange reserves implies that the PBOC must shift the monetary base to the banking system through the foreign exchange open market operation. This shift of the monetary base is completely endogenous: the central bank can only accept it passively and will be forced to adopt corresponding hedging measures. Thus, it is clear that one of the main reasons for excess liquidity in the banking sys- 
tem is the shifting of the monetary base caused by the rapid growth of counterpart foreign exchange reserves. Therefore, when the market is glutted with a substantial amount of liquidity, the effect on liquidity recovery caused by increasing the legal RRR will be very limited.

\section{Conclusions}

This study performed quantitative research on the policy effects of frequent RRR increases in China over the last five years based on the Johansen cointegration test, Granger causality test, and IRF analysis of the VAR model. We arrived at several important conclusions.

In the long run, a stable equilibrium relationship exists between the RRR and M2, CPI, and LS. In the short term, a one-way causality relationship exists between the RRR and M2, CPI, and LS, while an interacting relationship does not exist. Specifically, the RRR is the Grangercause of M2 and LS, and adjustment of the RRR will lead to variations in M2 and LS. However, between the variables RRR and CPI, CPI is the Granger-cause of RRR. Therefore, CPI variation will lead to active adjustment of the RRR by the PBOC.

Adjustment of the RRR has a long-term (but very weak) negative influence on M2 and LS. In addition, our results indicate that the impulse response values of M2 and LS on RRR variation will reach their maximum values when lagging for 4 - 7 months; the required reserves policy has an approximately 6-month time lag. However, adjustment of the RRR has almost no effect on the CPI. Therefore, in the inflation period, active RRR increases by the PBOC have not had an obvious effect on contracting liquidity and controlling the loan scale and have had no effect on curbing the tendency of the CPI to increase.

For several reasons, China's monetary policy regarding required reserves has not had a significant actual effect on dealing with excess liquidity, preventing inflation or controlling the increase of the loan scale. In theory, the RRR regulates the money supply mainly by influencing the monetary multiplier; however, in reality, the RRR has little impact on the monetary multiplier, as it is difficult to significantly change the value of the monetary multiplier, which influences the effect of the RRR as a monetary policy. Forced sales and purchases of foreign exchange also have considerable effects on the required reserves policy. Other factors include defects in China's required reserves system and enormously excessive commercial bank reserves.

The main function of the current required reserves policy in China is to control the money supply, although the actual effect of this policy is limited. The credit system in China is not well-developed, and as a relatively simple monetary policy, required reserves will play an important role in the future over a relatively long period of time.

This study's limitations must be addressed through further research. First, required reserves in China have remained at high levels in recent years, which is the opposite of the international trend of greatly reduced RRRs. It is necessary and reasonable to maintain a high level of required reserves in China. However, internationally, the functions of reserve fund systems have changed significantly; thus, it is necessary to conduct further research on the development of China's required reserves policy. Second, depending on the required reserves system presents fundamental difficulty in solving excess liquidity, inflation, and other problems. The integration of other monetary policy tools, development of other macroscopic readjustment and control policies, and the enhancement of the effectiveness of China's required reserves policy are problems worth researching in the future. Third, future studies must comprehensively address increases in the CPI, analyze the background of the increases and causes, and closely examine the factors that influence the $\mathrm{CPI}$, paying particular attention to whether the money supply has an impact on the CPI and whether excess liquidity directly causes increases in the CPI.

\section{REFERENCES}

[1] H. O. Hu and B. Ji, "Dissimilation of Reserve Fund System Functions and Development Direction of China's Reserve Fund Policy," Finance \& Economics, Vol. 33, No. 3, 2007, pp. 1-8.

[2] T. F. Richard and J. K. Kenneth, "A Note on Reserve Requirements and Monetary Control with a Flexible Deposit Rate," Journal of Banking \& Finance, Vol. 7, No. 1, 1983, pp. 101-109. doi:10.1016/0378-4266(83)90058-4

[3] S. E. Weiner, "The Changing Role of Reserve Requirements in Monetary Policy,” Economic Review-Federal Reserve Bank of Kansas City, Vol. 77, No. 4, 1992, pp. 45-63.

[4] B. S. Bernanke and H. Mihov, "Measure of Monetary Policy,” The Quarterly Journal of Economics, Vol. 113, No. 3, 1998, pp. 869-902. doi:10.1162/003355398555775

[5] E. M. Leeper, C. A. Sims and T. Zha, "What Does Monetary Do?” Brooking Paper on Economic Activity, 1996, pp. 1-63.

[6] H. S. Gordon and E. W. Stuart, "Monetary Policy without Reserve Requirements: Case Studies and Options for the United States," Economic Review-Federal Reserve Bank of Kansas City, Vol. 82, No. 2, 1997, pp. 25-26.

[7] D. H. James, "The Supply and Demand for Federal Reserve Deposits," Carnegie-Rochester Conference Series on Public Policy, Vol. 49, No. 4, 1998, pp. 1-44.

[8] M. Goodfriend, "Interest on Reserves and Monetary Policy,” FRBNY Economic Policy Review, Vol. 19, No. 3, 2002, pp. 33-45.

[9] J. Tobin and W. C. Brainard, "Financial Intermediaries and the Effectiveness of Monetary Controls," American 
Economic Review, Papers and Proceedings of 75th Annual Meeting of the American Economic Association, 1963, p. 53.

[10] B. C. Shi, "Required Reserves Policy and Money Supply,” Shanghai Finance, Vol. 29, No. 5, 2008, pp. 43-45.

[11] Z. F. Luo, "Operation of Required Reserves Policy of People's Bank of China and Analysis of Effects," Reform of the Economic System, Vol. 28, No. 6, 2010, pp. 96100.

[12] L. H. Wu, "Effectiveness Evaluation of Constant RRR Increase in China," Journal of Shanghai Finance University, Vol. 17, No. 4, 2010, PP. 23-29.

[13] F. B. Zhao and J. Y. Zhao, "Analysis of Macroscopic Effect of RRR Increase of People's Bank of China," Journal of Shanghai Business School, Vol. 9, No. 1, 2008, PP. 1-8.

[14] Z. Li, "Analysis of China's RRR Adjustment and Existing Problems," Journal of Beijing Technology and Busi- ness University, Vol. 28, No. 5, 2008, pp. 92-97.

[15] G. G. Yang, "Analysis of Influencing Factors of China's RRR Policy Effect,” Economic Perspectives, Vol. 15, No. 4, 2008, pp. 53-58.

[16] J. Cui and X. Liu, "Mechanism of Action and Effectiveness of China's Required Reserves System,” Statistics and Decision-Making, Vol. 29, No. 6, 2009, pp. 122-124.

[17] The People's Bank of China, 2011. http://www.pbc.gov.cn

[18] The National Bureau of Statistics, 2011. http://www.stats.gov.cn

[19] X. T. Zhang, "User Guide of Eviews and Cases,” China Machine Press, Beijing, 2008.

[20] Z. Zhao, "Why the Effect of Frequent Application of Required Reserves Tool by People's Bank of China Recently Is Not Obvious?” Finance \& Economics, Vol. 33, No. 9, 2007, pp. 8-14. 